\title{
A MARKOV CHAIN ANALYSIS OF EFFECT OF TRAFFIC LAW ENFORCEMENT ON ROAD TRAFFIC ACCIDENTS RATE IN OGUN STATE, NIGERIA
}

\author{
R. A. Folarin ${ }^{1, *}$ and M. K. Onifade ${ }^{2}$ \\ 1, 2, Dept of Management TeChnology, Bells University of TeChnology, OtA, Ogun State, NIGERIA \\ E-mail addresses: ${ }^{1}$ rasheedfolarin77@gmail.com, ${ }^{2}$ morakinyo.onifade@yahoo.com
}

\begin{abstract}
Ogun State is known for road traffic accidents and fatalities. Out of the 36 states in Nigeria, five states usually combine to give 50\% of accidents recorded in the country and Ogun State is among these states. Ten years accident and traffic violation data obtained from Ogun State Traffic Compliance and Enforcement Corps (TRACE) were used to assess the effect of traffic law enforcement on road traffic accidents rate in the state using Markov chain model. Markov chain model analysis revealed that drivers in Ogun State committed unsafe acts (overspeeding, Using mobile phone while driving and driving without driver's license) 55 times and unsafe condition (driving without using seatbelt) 16 times before experiencing fatality or permanent disability. The study also revealed that $46 \%$ of drivers that committed unsafe acts and $13 \%$ of drivers that committed unsafe condition left driving with fatality. While $176 \%$ of drivers that committed unsafe acts and $58 \%$ of drivers that committed unsafe condition left driving with permanent injury. From the result of the study, traffic law enforcement in Ogun state was not adequate and effective.
\end{abstract}

Keywords: Markov chain analysis, traffic law enforcement, road traffic accident, unsafe acts, unsafe conditions, fatality, permanent injury

\section{INTRODUCTION}

The United Nation General Assembly, in 2010 declared the period 2011-2020 as the Decade of Action for Road Safety, with the aim of reducing the rate of road traffic fatalities to the barest minimum around the world [1]. Most traffic management agencies responsible for ensuring safer roads have devised various ways of preventing road traffic accidents. In Nigeria, traffic law enforcement are been used to control road user behavior by preventive, persuasive and punitive measures in order to effect the safe and efficient movement of traffic.

According to the World Health Statistics [2] report, around 1.25 million people died from road traffic injuries in 2013, with another 20-50 million people sustaining non-fatal injuries as a result of road traffic accidents. Road traffic accidents is the ninth leading cause of death globally, and the leading cause among people age 15-29 years [2]. Next to insurgency, Road
Traffic Accident is the second highest sources of violent death in Nigeria. It is because of this ugly situation that Nigeria was ranked second highest in the rate of accidents among 193 countries of the world as reported by World Health Organization [3]. To further corroborate the alarming rate of road accident in Nigeria, the World Health Organization, adjudged Nigeria the most dangerous country in Africa with $33.7 \%$ death per 100,000 population every year. According to $\mathrm{WHO}$ one in every four road accidents in Africa occurs in Nigeria. Ogun State is known for road traffic accidents and fatalities, out of the thirty six (36) states in Nigeria, five (5) states usually combine to give fifty percent $(50 \%)$ of recorded accidents in the country and Ogun state is among these five (5) states [4].

Causes of motor vehicle crashes are multi-factorial and involve the interaction of a number of pre-crash factors that include people, vehicle and the road

* Corresponding author, tel: +234-803-424-2288 
environment [5]. Human error is estimated to account for between $64 \%$ and $95 \%$ of all causes of traffic crashes in developing countries like Nigeria [6]. Afolabi, et. al [7] attributed the increasing magnitude of fatal road traffic accident globally to population explosion and increased level of motorization. Sumaila [8] in his reviewed of traffic accidents and safety management in Nigeria found driver as the main culprit for the high rate of accidents and also the functional limitations of FRSC as the lead agency for road safety matters, the practical difficulties of implementing the driver license and vehicle registration schemes, and poor driving culture of Nigerians arising from weak traffic education, public awareness and enforcement programmes are other issues responsible high rate of accidents in Nigeria. Aparicio [9] and Ansari [10] also agreed that driver behavior is the leading contributor to road accidents. Globally, diverse measures are put in place to reduced road traffic accidents. For instance, in 2008 , the city of San Francisco reported a reduction of $50 \%$ accidents recorded in the first quarter year on year which was attributed to the introduction of double fines ranging for reckless driving causing bodily harm. Constant et. al [11] attributed the decline in road mortalities in France to the change in the drivers' attitude towards road traffic safety in embracing stricter regulations. Constant et al [11] bring into the picture an interesting debate that the law alone is not sufficient, but rather how well motorists receive it is what makes the difference. According to Richter et al [12] the United Kingdom experienced more significant drops in fatality rates than the USA by intensifying the use of speed camera networks.

Statistical tools are utilized to analyse road traffic accidents with the aim to understand the causes of road traffic accidents and achieve safer roads. Predominant among the tools are time series, regression and correlation [1]. Igboanugo [13] in his study adopted a Markov Chain analysis of accident data, to appraise the pattern of episodic incidence of industrial accidents in a typical oil and gas company in Nigeria oil-rich Niger Delta Basin. Shengneng [14] used Markov chain to predict the number of traffic accidents from 2016 to 2018 in Chinese Xinyang city, the results show that when using Grey Markov chain model, the average relative error reduced from the Grey model $5.14 \%$ to $1.34 \%$, the error reduction of $2.12 \%$.
Oseni and Anjorin [1] did analysis of the event history of road accident using the multi-state Markov model and discovered that progression to injury state is 5 times more likely than death. Also injured victims are $6 \%$ more likely to recover from the injury than die. However, the transition probabilities that a victim will die after 1,7 and 14 days of occurrence of the accident were obtained as $0.08,0.39$ and 0.61 respectively. Wang et al[15] make a Markov prediction on residual random sequence on the basis of grey prediction theory, which realizes the complementary advantages of two traditional models, the improved prediction model is analyzed by an example, and the results show that the improved Markov prediction model has high prediction accuracy.

Juan et al [16] modelled driver behaviour near intersections in Hidden Markov Model utilized the model to measure the stability and risk of driver behaviour. It was found that drivers' behaviours in the dilemma zone are of lower stability and higher risk compared with those in other regions around intersections.

Jian-yi et al [17] applied an amended Gray Markov chain theory to forecast the mine safety accident deaths from 1990 to 2010 in China, and predicted coal accident deaths from 2011 to 2014 . The results show that the new model not only discovers the trend of the mine human error accident death toll but also overcomes the random fluctuation of data affecting precision.

Constantinos et al [18] combines model-based clustering, variable-length Markov chains and nearest neighbour classification to make short-term speed prediction in a freeway network in Irvine, $C A$, which showed encouraging results. John et al [19] used Markov Chain Switching Approach to determine the probability of occurrence of road traffic accidents and the significant factors that affects the severity of a road traffic accident, the approach takes into consideration the heterogeneity of the variables and time-dependent constraints which are not considered by other regression techniques.

Most research on road traffic accidents have looked on the causes and analysis of accidents [6, 7, 20-23]. However, there is dearth of research on effect of traffic enforcement on road traffic accidents in Nigeria. This work adopts a Markov chain model to assess the effectiveness of traffic law enforcement in reducing accident rate in Ogun State 
Markov Chain Model is a predictive tool and can be applied in various areas ranging from transportation, manufacturing, to oil and gas industries. Road traffic accidents analysis can be done by using SPSS, fuzzy logic, artificial neural network and Microsoft Excel. However, Markov chain approach offers an intuitive appeal than others [24].

Markov chain modelling is one of the most potent for analyzing the complex stochastic system. The versatility of Markov chain is widely acclaimed.

\section{METHODOLOGY}

A ten year data (2008-2017) of Road Traffic Accidents and Traffic Law Enforcement Violation comprising six state spaces (S): Fatality $\left(S_{1}\right)$, Permanent Injury $\left(S_{2}\right)$, Overspeeding $\left(S_{3}\right)$, Driving without using seatbelt $\left(S_{4}\right)$, Using mobile phone while driving $\left(S_{5}\right)$, Driving without driver's licence $\left(S_{6}\right)$ were obtained from Ogun State Traffic Compliance and Enforcement Corps (TRACE).

Accidents states spaces are:

$\left\{S_{1}, S_{2}, S_{3}, S_{4}, S_{5}, S_{6},\right\}$

$\left\{S_{1}, S_{2}\right\}=$ Absorbing

$\left\{S_{3}, S_{4}, S_{5}, S_{6}\right\}=$ Non - absorbing transient

The six stages observed in Table 1 were further condensed into four states whose states space, $\mathrm{S}$ is

$$
S\left\{S_{1}, S_{2}, S_{3}, S_{4}\right\}
$$

where

$\mathrm{S}_{1}=$ fatality (absorbing)
$\mathrm{S}_{2}=$ Permanent disability (PD)

$\mathrm{S}_{3}=$ Unsafe act (non absorbing), \{Over Speeding, using mobile phone and driving without driver's licence\}

$\mathrm{S}_{4}=$ Unsafe Condition (non-absorbing), \{Driving without using seatbelt\}

\subsection{Theoretical Brief}

A situation can be modelled by a Markov chain if it can be viewed as the repeated movement (trials) of one or more objects among various classification, or

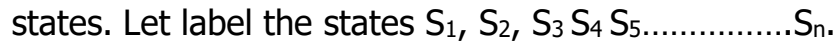
For each pair $\left(\mathrm{S}_{\mathrm{i}}, \mathrm{S}_{\mathrm{j}}\right)$, let a fixed proportion $P_{i j}$ of object located at $S_{i}$ move to $S_{j}$ during each step, or movement.

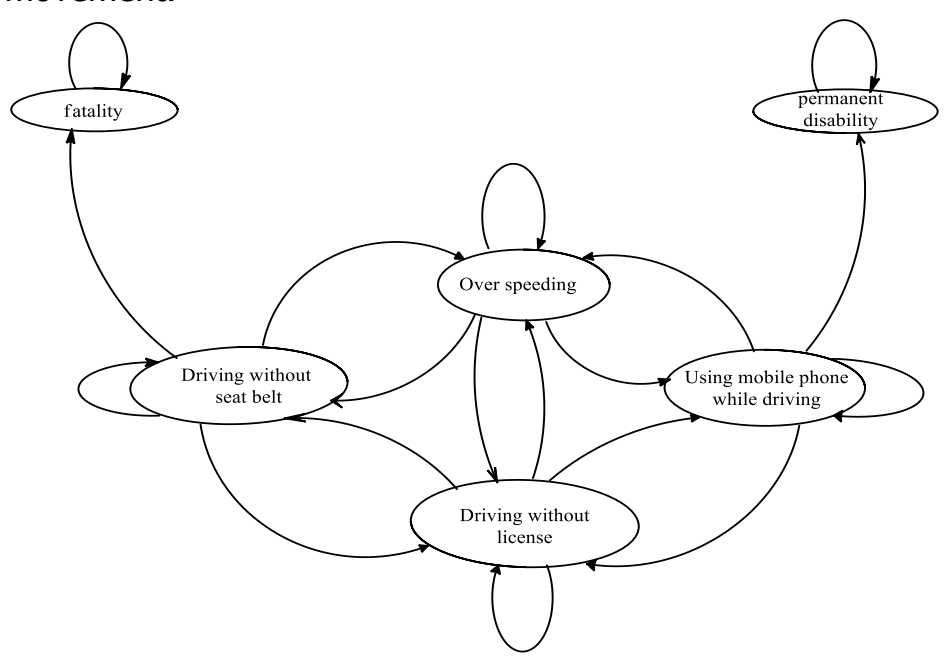

Figure 1: Markov Transition Diagram (Adapted from Igboanugo [13])

Table 1: Road Traffic Accident Data and Traffic Law Violation Data

\begin{tabular}{|c|c|c|c|c|c|c|c|c|c|c|c|c|}
\hline $\mathrm{S} / \mathrm{N}$ & States & 2008 & 2009 & 2010 & 2011 & 2012 & 2013 & 2014 & 2015 & 2016 & 2017 & TOTAL \\
\hline 1 & Fatality & 180 & 150 & 68 & 92 & 123 & 113 & 129 & 206 & 131 & 200 & 1392 \\
\hline 2 & Permanent Disability & 512 & 533 & 424 & 350 & 422 & 712 & 742 & 839 & 717 & 996 & 6247 \\
\hline 3 & Over Speeding & 2656 & 2709 & 3780 & 3731 & 3583 & 3608 & 3148 & 2438 & 2308 & 1767 & 29728 \\
\hline 4 & $\begin{array}{l}\text { Driving without } \\
\text { using Seatbelt }\end{array}$ & 1871 & 1458 & 2079 & 2190 & 2317 & 2961 & 2177 & 1612 & 1526 & 1369 & 19560 \\
\hline 5 & $\begin{array}{l}\text { Using Mobile Phone } \\
\text { while driving }\end{array}$ & 1782 & 2012 & 2586 & 2296 & 3263 & 3204 & 2359 & 1480 & 1506 & 1611 & 15052 \\
\hline 6 & $\begin{array}{l}\text { Driving without } \\
\text { Diver's license }\end{array}$ & 1138 & 1250 & 1458 & 1690 & 1482 & 3082 & 1165 & 1153 & 1423 & 1209 & 22099 \\
\hline
\end{tabular}

Source: [25]

Table 2: Incidence Data in Four States

\begin{tabular}{ccccccccccccc}
\hline S/N & STAGE & 2008 & 2009 & 2010 & 2011 & 2012 & 2013 & 2014 & 2015 & 2016 & 2017 & TOTAL \\
\hline 1 & S1 & 180 & 150 & 68 & 92 & 123 & 113 & 129 & 206 & 131 & 200 & 1392 \\
2 & S2 & 512 & 533 & 424 & 350 & 422 & 712 & 742 & 839 & 717 & 996 & 6247 \\
3 & S3 & 5576 & 5971 & 7824 & 7717 & 8328 & 9896 & 6672 & 5071 & 5237 & 4587 & 66879 \\
4 & S4 & 1871 & 1458 & 2079 & 2190 & 2317 & 2961 & 2177 & 1612 & 1526 & 1369 & 19560 \\
\hline
\end{tabular}


Thus the scenario can be represented in a transition probability matrix as

$$
\begin{aligned}
& \begin{array}{llll}
S_{1} & S_{2} & \ldots & S_{K}
\end{array} \\
& T=\begin{array}{c}
S_{1} \\
S_{2} \\
\ldots \\
S_{K}
\end{array}\left[\begin{array}{cccc}
P_{11} & P_{12} & \ldots & S_{K} \\
P_{21} & P_{22} & \ldots & P_{1 K} \\
\ldots & \ldots & \ldots & \ldots \\
P_{K 1} & P_{K 2} & \ldots & P_{K K}
\end{array}\right]
\end{aligned}
$$

$T_{i j}=P_{i j}=$ probability that an object in state $i$ move, to state $j$,

\section{Theorem 1}

An object from an initial distribution $d_{0}$ in a Markov chain, can move through many transitions to attain a long-run distribution, $d_{n}$ and hence achieve a stable transition distribution probability matrix $\overline{T_{L}}$ with stabilized distribution.

$$
d_{n}=d_{o} T^{n}
$$

\section{Theorem 2}

Thus, if as the number of transitions increase $(n \uparrow)$, the powers $T^{n}$ as the transition matrix $T^{n}$ approach a matrix $\bar{T}$, then for each choice of an initial distribution $d_{o}$, the subsequent distributions $d_{n}=d_{o} T^{n}$ stabilize to the long run distribution given by

$$
\bar{d}=d_{o} \bar{T}
$$

Moreover, each $\bar{d}$ arising in this fashion is stationary

\section{Theorem 3}

Let $\mathrm{T}$ be the transition matrix of a regular Markov chain. Then the power of T approach a matrix $T^{-}$ with long-run distributed all of whose rows are identical and all enters positive.

There remains the practical problem of actually computing the unique long-run distribution $\bar{d}$ associated with $\bar{T}$ of regular Markov chain.

$d=d T$

for stationary $\mathrm{d}$ and regular $\mathrm{T}$
$=\mathrm{dI}=\mathrm{dT}$

$=\mathrm{dI}-\mathrm{dT}=0$

and $\mathrm{d}(\mathrm{I}-\mathrm{T})=0$

Take the transpose

$$
\Rightarrow \theta(I-T)^{t} d^{t}=0^{t} \Leftarrow A X=0
$$

Equation (3) is a homogeneous system.

This leads us to theorem 4

\section{Theorem 4}

Every Markov chain with $\kappa$ states has at least one long-run distribution. Moreover, each longrun distribution is the transpose of a solution to:

$\mathrm{AX}=0$

Whose entries sum to 1 . Here

$$
A=(I-T)^{t},
$$

$\mathrm{T}=\kappa$ - by $-\kappa$ transition matrix and both $\mathrm{X}$ and 0 are $\kappa$ - by- 1 column vectors.

\section{Theorem 5}

Consider as absorbing Markov chain with transition matrix.

$$
\bar{T}=\underset{\text { Nonabsorbing }}{\text { Absorbing }}\left[\begin{array}{ccc}
I & - & O \\
- & - & - \\
(-Q)^{-1} R & - & O
\end{array}\right]
$$

The $i^{\text {th }}$ row of the sub matrix $B=(I-Q)^{-1} R$ specify the long-run distribution of objects among the various absorbing states provided all objects start in the $i^{\text {th }}$ Non-absorbing state.

\section{Assumptions:}

(i) A driver cannot transit from $S_{4}$ directly to $S_{1}$ $(P=0)$, the transition is periodic. This is assured by not allowing a driver without driver's licence to drive a vehicle that can expose him/her to fatal accidents.

(ii) A driver who frequently over-speeds, drive without using seatbelt and use mobile phone while driving has some probability of moving to absorbing state of permanent injury or fatality.

(iii) Probabilities in absorbing states $S_{1}-S_{2}$ are heuristically determined i.e. the chances that a driver who is dead on account of accident will come back to state of permanent injury is quite remote. 


\subsection{Calculation of the Transition Probability Matrix (TPM)}

Based on Baye's Probability, the elements of the TPM for non-absorbing states were calculated as shown below.

$\begin{array}{ll}\text { Fatalities }\left(S_{1}\right) & =1392 \\ \text { Unsafe Acts }\left(S_{3}\right) & =66879 \\ \text { Unsafe Condition }\left(S_{4}\right) & =19560 \\ \text { Total } & =87831\end{array}$

$P\left(S_{1}\right)=\frac{1392}{87831}=0.0159$

$P\left(S_{3}\right)=\frac{66879}{87831}=0.7615$

$P\left(S_{4}\right)=\frac{19560}{87831}=0.2227$

Permanent Disability $\left(S_{2}\right)=6247$

Unsafe Acts $\left(S_{3}\right) \quad=66879$

Unsafe Condition $\left(S_{4}\right)=19560$

Total $\quad=92686$

$P\left(S_{2}\right)=\frac{6247}{92686}=0.0674$

$P\left(S_{3}\right)=\frac{66879}{92686}=0.7216$

$P\left(S_{4}\right)=\frac{19560}{92686}=0.2110$

Table 3: Transition probability table (TPM)

\begin{tabular}{ccccc}
$\begin{array}{c}\text { Erom } \\
\text { To }\end{array}$ & $\mathrm{S}_{1}$ & $\mathrm{~S}_{2}$ & $\mathrm{~S}_{3}$ & $\mathrm{~S}_{4}$ \\
\hline $\mathrm{S}_{1}$ & 1 & 0 & 0 & 0 \\
$\mathrm{~S}_{2}$ & 0 & 1 & 0 & 0 \\
$\mathrm{~S}_{3}$ & 0 & 0.0159 & 0.7615 & 0.2227 \\
$\mathrm{~S}_{4}$ & 0.0674 & 0 & 0.7216 & 0.2110 \\
\hline
\end{tabular}

In compact form:

$T=\left[\begin{array}{cccc}1 & 0 & 0 & 0 \\ 0 & 1 & 0 & 0 \\ 0 & 0.0159 & 0.7615 & 0.2227 \\ 0.0674 & 0 & 0.7216 & 0.2110\end{array}\right]$

And in canonical form:

$T=\left[\begin{array}{ccccccc} & 1 & 0 & \vdots & 0 & 0 & \\ & 0 & 1 & \vdots & 0 & 0 & \\ \hline 0 & 0.0159 & \vdots & 0.7615 & 0.2227 \\ 0.0674 & 0 & \vdots & 0.7216 & 0.2110\end{array}\right]$

$$
T=\left[\begin{array}{ccc}
I & \vdots & 0 \\
\hline R & \vdots & Q \\
R & \vdots & Q
\end{array}\right]
$$

$I=\left[\begin{array}{ll}1 & 0 \\ 0 & 1\end{array}\right], \quad 0=\left[\begin{array}{ll}0 & 0 \\ 0 & 0\end{array}\right]$

$R=\left[\begin{array}{cc}0 & 0.0159 \\ 0.0674 & 0\end{array}\right], \quad Q=\left[\begin{array}{ll}0.7615 & 0.2227 \\ 0.7216 & 0.2110\end{array}\right]$

Computation $\mathrm{N}$ : Which is the number of habituations drivers make in a particular non-absorbing state. Set

$$
I-Q=\left(\begin{array}{ll}
a & c \\
b & d
\end{array}\right)
$$

Where $a, b, c$ and $d$ are elements of matrix I-Q. Then

$$
(I-Q)^{-1}=\left(\frac{1}{a d-b c}\right)\left(\begin{array}{cc}
d & -c \\
-b & a
\end{array}\right)=N
$$

But $R=\left(\begin{array}{cc}0 & 0.0159 \\ 0.0674 & 0\end{array}\right)$

$(I-Q)=\left[\left(\begin{array}{ll}1 & 0 \\ 0 & 1\end{array}\right)-\left(\begin{array}{ll}0.7615 & 0.2227 \\ 0.7216 & 0.2110\end{array}\right)\right]$

$(1-Q)=\left[\begin{array}{cc}0.2385 & -0.2227 \\ -0.7216 & 0.7890\end{array}\right]$

$N=(1-Q)^{-1}$

$=\left[\frac{1}{.1882-0.1607}\right]\left[\begin{array}{cc}0.7890 & -(-0.7216) \\ -(-0.2227) & 0.2385\end{array}\right]$

$N=\frac{1}{0.0275}\left[\begin{array}{ll}0.7890 & 0.7216 \\ 0.2227 & 0.2385\end{array}\right]$ or $N=\left[\begin{array}{cc}28.69 & 26.24 \\ 8.25 & 8.67\end{array}\right]$ Next, we compute the expected number of times an absorbing chain (driver) spends among transient states (non-absorbing states) before passing to the absorbing states $S_{1}$ or $S_{2}$ given that it starts in $S_{3}$, and $\mathrm{S}_{4}$

$$
\begin{aligned}
& t=N \varepsilon \\
= & {\left[\begin{array}{cc}
28.69 & 26.42 \\
8.25 & 8.67
\end{array}\right]\left[\begin{array}{l}
1 \\
1
\end{array}\right]=\left[\begin{array}{c}
{[(28.69)(1)+(26.42(1)]} \\
{[(8.25)(1)+(8.67)(1)]}
\end{array}\right] } \\
= & {\left[\begin{array}{l}
55.11 \\
16.92
\end{array}\right] }
\end{aligned}
$$

$$
t_{2}(2 N-I) t-t_{s q}
$$

$\left[2\left(\begin{array}{cc}28.69 & 26.42 \\ 8.25 & 8.67\end{array}\right)-\left(\begin{array}{ll}1 & 0 \\ 0 & 1\end{array}\right)\right]\left(\begin{array}{c}55.11 \\ 16.92\end{array}\right)-\left(\frac{55.11^{2}}{16.92^{2}}\right)$

$=\left(\begin{array}{cc}56.38 & 52.84 \\ 16.5 & 16.34\end{array}\right)\left(\begin{array}{c}55.11 \\ 16.92\end{array}\right)-\left(\begin{array}{c}3037.11 \\ 286.29\end{array}\right)$

$=\left[\begin{array}{c}(56.38)(55.11)+(52.84)(16.92) \\ (16.5)(55.11)+(16.34)(16.92)\end{array}\right]-\left[\begin{array}{c}3037.11 \\ 286.29\end{array}\right]$

$=\left[\begin{array}{c}4001.15 \\ 1185.81\end{array}\right]-\left[\begin{array}{c}3037.11 \\ 286.29\end{array}\right]=S_{4}\left[\begin{array}{l}964.04 \\ 899.52\end{array}\right]$

Here we evaluate the probability that the worker is absorbed in $S_{1}$ or $S_{2}$ given that he starts in $S_{3}$, and $S_{4}$ $B=N R=N d_{0}=\left[\begin{array}{cc}28.69 & 26.24 \\ 8.25 & 8.67\end{array}\right]\left[\begin{array}{cc}0 & 0.0159 \\ 0.674 & 0\end{array}\right]$

$$
\boldsymbol{B}=\left[\begin{array}{cc}
\{(28.69(0)+(26.24)(0.0674)\} & \{(28.69(0.0159)+(26.24)(0)\} \\
\{(8.25)(0)+(8.67(0.0674)\} & \{(8.25)(0.0159+(8.67)(0)\}
\end{array}\right]
$$


$\boldsymbol{B}=\left[\begin{array}{ll}1.769 & 0.456 \\ 0.584 & 0.131\end{array}\right]$

The matrix $B$ provides the long run distribution of fatality and permanent injury.

\subsection{Results}

From the above results, we can deduce the following:

(i) Number of habituations drivers make in a particular non-absorbing state

a. $4 \rightarrow 3$ with entry 8.25: drivers in this category committed unsafe acts not less than 8 times while in absorbing state.

b. $4 \rightarrow 4$ with entry 8.67: drivers in this category committed unsafe condition average of nine times while in absorbing state.

(ii) The total number of habituations drivers undertook among all the two non-absorbing states before being trapped in any of absorbing states. The associated standard variance, represented by $\tau_{2}$ are also shown.

The matrix $\tau=\left[\begin{array}{l}55.11 \\ 16.92\end{array}\right]$ revealed that generally, irrespective of the starting state, drivers undergo on the average 36 transition between the two nonabsorbing states before being trapped in any of absorbing states. However these estimates are subject to a standard deviation of $\sqrt{\tau_{2}} \approx 30$.

(iii) Transition from non-absorbing to absorbing state From equation (11), (B) showed that $46 \%$ of drivers that committed unsafe acts and $13 \%$ of drivers that committed unsafe condition left driving with fatality. While $176 \%$ of drivers that committed unsafe acts and $58 \%$ of drivers that committed unsafe condition left driving with permanent injury.

\subsection{Discussion}

Markov chain model applied in this study has enabled us to know the trends in road traffic accidents in Ogun State. Reference to matrix $B$, the long run drivers safety implication of the stabilized matrix is that in the past 10 years, $46 \%$ of drivers that committed unsafe acts and $13 \%$ of drivers that committed unsafe condition left driving with fatality. While $176 \%$ of drivers that committed unsafe acts and $58 \%$ of drivers that committed unsafe condition left driving with permanent injury. It is evident from the analysis that on the average, drivers had committed 55 to 16 unsafe acts or unsafe condition without been caught or when caught the fines was not severe enough to prevent them from committing traffic offences, before experiencing real accident (fatality or permanent disability). The likely implication of this result is that traffic law enforcement in Ogun State is not adequate and effective. This is because in Nigeria most traffic law enforcement agencies safety programmes are inadequate due to lack of necessary logistics, adequate manpower and use of modern technology like automated speed and red light violation cameras. Factors like lack of publicity to support enforcement operations, traffic law enforcement officer training and driver's education program may account for the high rate of accidents and fatalities.

A good traffic law enforcement should achieve safer road user behavior through compliance with traffic laws. Traffic offences deterrence-based approaches such as traffic monitoring CCTV cameras and random breath testing of drivers should be done [12]. Enforcement of traffic laws and ensuring payment of stipulated fees by traffic offenders will go a long way in refraining drivers from violating traffic laws [11].

\section{CONCLUSION AND RECOMMENDATIONS}

The study revealed that traffic law enforcement is not adequate and efficient in reducing accident rate in Ogun State, as drivers still committed traffic offences (overspeeding, using mobile phone while driving, driving without license and driving without using seatbelt) on average of 36 times without been caught before experiencing real accidents and either died or become permanently disabled. It further revealed that on average $46 \%$ of drivers in the state left driving through fatality and permanent injury while $58 \%$ of drivers remained driving in the state and continues to commit traffic offences (unsafe acts and unsafe condition). There is need for traffic management agencies in the state to review their traffic management strategy so as to reverse the unpleasant trend.

Base on the findings of this study, the following recommendations are provided as follows:

i. Traffic management organization should be adequately funded to afford technology and equipments that is required to make enforcement efficient.

ii. Traffic offences deterrence-based approaches such as traffic monitoring CCTV cameras and random breath testing of drivers should be done [12]

iii. There should be stricter penalty for major traffic offences committed by drivers

iv. Enforcement of traffic laws and ensuring payment of stipulated fees by traffic offenders 
will go a long way in refraining drivers from violating traffic laws [11].

v. Adoption of system approach or safe system, which look at what can be done differently to make our roads and roadsides more forgiven like ensuring appropriate speed, use of more safer vehicle among others

vi. Capacity development for road traffic officers.

\section{REFERENCES}

[1] Oseni, B. M. \& Anjorin I. H. "Modelling of Road Traffic Accidents: A Multi-state Markov Approach". Sri Lankan Journal of Applied Statistics, Vol. 2016 (17-2).

[2]World Health Statistics (2016). Monitoring Health for Sustainable Development Goals (SDGs).

[3]World Health Organization (2012). Road Traffic Accident in Developing Countries.

[4] Oyesiku, O. K., (2018). "A System Approach to Human Capital Development For The Attainment Of The Goals Safety Vision 2020 Agenda". A Guest Speaker Presentation on the $3^{\text {rd }}$ TRACE Corps Commander Conference on $1^{\text {st }}$ December, 2018.

[5] Haddon W. "Advances in the epidemiology of injuries as a basis for public policy". Public Health Report, 1980, 95:411-421.

[6] Atubi, A. O. "Road Traffic Accident Variation in Lagos State, Nigeria: A synopsis of Variance spectra". Journal of African Research Review, Vol. 4, 2010, NO. 2 PP 197-218.

[7] Afolabi, J. O. \& Gbadamosi, K. T. "Road traffic crashes in Nigeria: Causes and consequences". Transport \& Logistics: the International Journal, Volume 17, 2017, Issue 42.

[8] Sumaila, A. F. "Road crashes trends and safety management in Nigeria". Journal of Geography and Regional Planning, Vol. 6(3), 2013, pp. 53-62.

[9] Aparicio, I.F., Arenas, R.B., Mira, M.J.M. \& Páez, A.J. "The endurance of the effects of the penalty point system in Spain three years after. Main influencing factors". Journal of Accident Analysis and Prevention. 43(3), 2011:911-22.

[10] Ansari, S., Akdaar, F., Mandoorah, M. \& Moutaery, K. "Causes and effects of road traffic accidents in Saudi Arabia". Public Health. 114, 2000:37-39.

[11]Constant, A., Salmi, L.R., Lafont, S., Chiron, M. \& Lagarde, E. "The recent dramatic decline in road motarlity in France: how drivers' attitudes towards road traffic safety changed between 2001 and
2004 in the Garzel cohort". Health Education Research. 23(5), 2008:848-58.

[12] Richter, E.D., Friedman, L.S., Berman, T. \& Rivkind, A. "Death and injury from motor vehicle crashes: a tale of two countries". American Journal of Preventive Medicine. 29(5), 2005:440-49.

[13] Igboanugo A. C. "Markov Chain Analysis of Accident Data: The Case of an Oil and Gas Firm in the Niger Delta Area of Nigeria". International Journal of Engineering Research in Africa, Vol. 1 (2010) pp. 29-38.

[14] Shengneng, H. "Prediction of city traffic accidents based on grey Markov chain model". Revista de la Facultad de Ingeniería U.C.V., Vol. 32, 2017, pp. 144-151.

[15] Wang, W., Jing, Y., Zhanbo, L., Gang, L. "Research on Accident Prediction in Chemical Industry based on Improved Markov Model". Chemical Engineering Transactions, Vol. 59, 2017

[16] Juan Li *, Qinglian He, Hang Zhou, Yunlin Guan and Wei Da. "Modeling Driver Behavior near Intersections in Hidden Markov Model". Int. J. Environ. Res. Public Health, Vol. 13, 2016, 1265.

[17] Jian-yi Lan and Ying Zhou. "Application of Gray Markov SCGM $(1,1)$ C Model to Prediction of Accidents Deaths in Coal Mining". International Scholarly Research Notices, Volume 2014,

[18]Constantinos Antoniou, Haris N. Koutsopoulos and George Yannis. "Traffic state prediction using Markov chain models". Proceedings of the European Control Conference, Kos, Greece, July 25, 2007.

[19]John Carlo F. Marquez, Darwin Joseph B. Ronquillo, Noime B. Fernandez and Venusmar C. Quevedo, (2017). "Analysis of Vehicle Crash Injury-Severity in a Superhighway: A Markovian Approach". Journal of Industrial Engineering and Management Science, Vol. 1, 2017:33-48.

[20] Chador W, Mongal S. G, Tashi D, Ewan W, Zaw M. T \& Jaya P. T. Journal Of Injury Control And Safety Promotion, VOL. 25, NO. 1, 2018: 65-69.

[21] Micheale, K. G. "Road Traffic Accident: Human Security Perspective". International Journal of Peace and Development Studies, Vol. 8(2), 2017: pp. 15-24.

[22] Eze, B. "Road Traffic Accidents in Nigeria: A Public Health Problem". AFRIMEDIC Journal, Volume 3, No. 2, July -December, 2012.

[23] Ohakwe, J., Iwuese, I. S., \& Chikezie, D.C. "Analysis of Road Traffic Accidents in Nigeria, A case study of Obinze/Nekede/Iheagwa Road in 
A Markov Chain Analysis of Effect of TrafFic Law Enforcement On Road Traffic AccidentS..., $\quad$ R. A. Folarin \& M. K. Onifade

Imo State, Nigeria". Asian Journal of Applied Science, 4(2), 2011: 166 - 175, 2011 ISSN 1996 $-3343$.

[24]Igboanugo, A, C and Onifade, M. K. Markov Chain Analysis of Manpower Data of a Nigerian University. Journal of Innovative Research in
Engineering and Science, 2(2), 2011, 107-123. ISSN: 2141-8225.

[25] TRACE CORPS (2018): Monthly Situation Report of Activities, Compiled by Directorate of Planning Research and Statistics, Ogun State Traffic Compliance and Enforcement Corps. 